\title{
Use of Herbal Medicines on Coronavirus
}

\section{Tanya Dudani* ${ }^{*}$ and Ayush Saraogi ${ }^{2}$}

${ }^{1}$ Master of Pharmacy, Shri Ram Group of Institutions, Jabalpur, Madhya Pradesh, India

${ }^{2}$ Post Graduate Diploma in Pharmaceutical Management, S.I.E.S College of Management Studies, India

*Corresponding Author: Tanya Dudani, Master of Pharmacy, Shri Ram Group of Institutions, Jabalpur, Madhya Pradesh, India.
Received: March 19, 2020

Published: March 24, 2020

C) All rights are reserved by Tanya Dudani and Ayush Saraogi.

\begin{abstract}
Coronavirus disease (CoViD-19) is basically a respiratory infection caused by a group of viruses infecting respiratory pathway, lungs and it can spread from animal to person, person to person while sneezing or physical contact. Its common symptoms includes cough, cold, fever and sore throat. Herbal medicine is a class of medicine originating from nature hence causing less side effects because of less use of additives, preservatives or excipients. I chose writing a review over the use of herbs for the treatment of Coronavirus because of rapid spread of the infection, availability of less knowledge regarding the treatment and increased concern of public to protect themselves from the effect of viral infection and preventing the use of allopathic medicines.
\end{abstract}

Keywords: Herbal; Allopathic; Coronavirus; Efficacy

\section{Introduction}

Corona virus is caused by rapidly dividing virus which works by injecting it's genome into other's gene and multiplies there hence it depends on other organisms for its growth and therefore makes it more difficult to vanish the disease-causing agent and it is becoming a great topic of research among the drug developers, researchers and scientists. When a patient is treated with a herbal drug, the continuous observation of treatment and it's effect becomes prerequisite to alter the dose as and when required on the basis of effects observed by the herbal practitioner. There is no scientific evidence for any of these alternative remedies like TCM (traditional Chinese medicine) and herbs to prevent or cure the illness caused by this virus, in fact, some of them may cause side effects. After the outbreak, Guangdong had reported a mortality of just $0.1 \%$ of infected people - compared with Wuhan's rate of $2.6 \%$ - and none of the confirmed patients in Zhejiang had died, the reason is that the patients in Guangdong and Zhejiang were given herbal drinks to relieve symptoms even before they were testing positive. When observed the areas were herbal treatment was administered, reported less number of deaths as compared to the areas were herbs were not administered. There is plenty of data supporting the effectiveness of herbs in treating viral infection but it is difficult to tell exactly how well herbs perform because in most cases they are administered with modern pills and some patients in critical condition are also supported with technical life support such as artificial lungs. The combination of modern and traditional therapy can no- tably reduce the intensity of symptoms, death rate and side effects as observed in China. The patients admitted first in China recovered completely from the infection and they were given a treatment that combined modern medicine and herbal remedies. Based on the laboratory in vitro studies, the Institute of China discovered Shuanghuanglian oral liquid that could be used to inhibit the 2019-nCoV. Use of herbal drugs and traditional methods is making it more difficult to ascertain which method is more beneficial among the modern drug or herbal remedies because of the mixed opinions received. The use of herbs is supported by many on the basis of their personal experience, some remained highly skeptical, if not hostile. Since this virus strain is not available to any laboratory in India, it is inconceivable that any preclinical or clinical testing is done in such a short period of time. For present, it appears inappropriate and premature to recommend any alternative therapies for what appears like a looming epidemic. As the scientists are still struggling for claiming the efficacy, recommendation of untested and unproven medications by health authorities can be misleading and potentially dangerous, few preventive measures can be advised but not treatment advice.

\section{Herbs responsible for treating Corona virus infection}

Out of all the natural compounds assayed, 13 were tested positive for treating 2019-nCoV which are also present in traditional Chinese medicine. Afterwards, out of these 13 compounds 2 or more were found to be present among 125 Chinese herbs, out of 
which 26 herbs are basically categorized for treatment of breathing respiratory infections caused by the virus. Among other 22 medicinal herbal extracts assayed, Cimicifuga rhizoma, Meliaecortex, Coptidis rhizoma, Phellodendron cortex and Sephorasubstrata radix reduced the MHV (mouse hepatitis virus) produced and the intracellular viral RNA and protein expression with EC50 (effective concentration) from 2.0 - $27.5 \mathrm{micron} / \mathrm{ml}$. They also reduced PEDV (porcine epidemic diarrhoea virus) production and VSV (vesicular stomatitis virus) production in vitro. These extracts inhibited MHV production to a great extent and can also be used as anti-coronaviral drugs.

Shuanghuanglian, discovered in China's medical Institute, which is a blend of Forsythia, Chinese skull cap and Honeysuckle is categorized as antiviral, antibacterial and found to be good for the immune system. It is also used for treating common symptoms such as fever, cough and sore throat. But still, we are not clear with the actual chemical constituent present in the preparation responsible for treating the infection. In a paper titled, "Study progress on Antiviral activities and mechanism of Flavonoids in Traditional Chinese medicine and natural medicines", it is stated that the Flavonoid extracted from the Litchi seeds can be used for treating the symptoms of SARS-CoV3CL by inhibiting the proteinase activity which is essential for viral protein synthesis

\section{Traditional Chinese medicine effect reports}

After the outbreak of severe acute respiratory syndrome (SARS), which occurred in 2002-03, World Health Organization started investing in huge number for knowing the efficacy of herbal medicine. The factories in Hubei started producing herbal drinks in large amount and in fast rate for the isolated, quarantined citizens suspected to be infected with the virus, the drink to be used for distribution was first boiled and then was packed in plastic containers, in Wuhan 1 plant could be used to meet the daily requirement of 30,000 patients, according to the People's Daily, a local newspaper. A research study conducted by the Chinese University of Hong Kong which also involved local patients suggested herbal treatment as, "a safe, efficacious and affordable severe acute respiratory syndrome (SARS) prevention measure, "also supported by the information on World Health Organization website.

"A team in Guangzhou had treated more than 50 patients and none of them later developed severe symptoms. In Shanghai, the patients who were administered combined treatment usually took 7 or 8 days to test negative (for the corona virus). Without herbal medicine, it could take more than 10 days, stated by Zhang, a member of the national expert panel while advising the central government regarding traditional Chinese medicine in a press conference. In Guangzhou, all of the 58 patients recovered with no infectious effect on the medical staff treating them. After the knowledge of full genome sequence of the infection causing agent, a research team with the help of Chinese Academy of Sciences in Shanghai produced a list of around 12 - 15 herbs that could suppress the vi- ral strain by studying their interaction with herbs in computer using computer-aided drug design (CADD) technology. The research empowered China to fight against the coronavirus with the help of technology and knowledge of herbs. Some of the patients infected with novel coronavirus (2019-nCoV) were found to be cured with traditional Chinese medicine or with combination of herbal and allopathic medicine in Jinyinthan Hospital in Wuhan from where the Coronavirus started.

The patients were treated by Traditional Chinese Medicine doctors from Beijing's Xiyuan and Guanganmen Hospitals and they were also looking after the patients in Wuhan since the outbreak, both under the China Academy of Chinese Medical Sciences, as reported by Xinhua [1-5].

\section{Conclusion}

Herbal treatment can be used for treatment against coronavirus infection as it is the only alternative we are left with for now other than few allopathic medicines suspected to be effective and some life support systems supporting the functioning of lungs and also because of following reasons - Few positive results observed by administering herbal drugs.

Unavailability of an allopathic drug.

Lack of knowledge of the viral strain responsible for causing infection.

The herbs are found to work best only when combined with modern medicine and life support system under proper observation. The research must be carried on rapidly to investigate the chemical constituent completely effective for treating the infection till then herbs must be administered to treat the infection and prevent it's spread while keeping the side effects of herbs in mind.

\section{Acknowledgment}

My sincere thanks to my college colleagues, faculty and management for their support.

\section{Conflict of Interest}

The author declares no conflict of interest.

\section{Bibliography}

1. Deng-hai Zhang., et al. "In silico screening of Chinese herbal medicines with the potential to directly inhibit 2019novel coronavirus". Journal of Integrative Medicine 18.2 (2020): 152158.

2. Coghlan ML., et al. "Combined DNA, toxicological and heavy metal analyses provides an auditing toolkit to improve pharmacovigilance of traditional Chinese medicine (TCM)". Scientific Reports 5 (2015): 17475.

3. Guangdi L and De Clercq E. "Therapeutic options for the 2019 novel coronavirus (2019-nCoV)". Nature Review Drug Discovery (2020). 
4. Sheahan TP., et al. "Comparative therapeutic efficacy of remdesivir and combination lopinavir, ritonavir, and interferon beta against MERS-CoV". Nature Communication 11 (2020): 222.

5. Holshue ML., et al. "First Case of 2019 Novel Coronavirus in the United States”. The New England Journal of Medicine (2020).

\section{Assets from publication with us}

- Prompt Acknowledgement after receiving the article

- Thorough Double blinded peer review

- Rapid Publication

- Issue of Publication Certificate

- High visibility of your Published work

Website: www.actascientific.com/

Submit Article: www.actascientific.com/submission.php

Email us: editor@actascientific.com

Contact us: +919182824667 